\title{
EFEITO DA ESTABILIDADE DE ESTOCAGEM DA LIPASE COMERCIAL DE Candida antarctica B (CALB) NA FORMA LIVRE E IMOBILIZADA POR CONFINAMENTO EM SUPORTE DE POLIURETANO
}

\author{
I. A. FERNANDES ${ }^{1}$; N. L. D. NYARI ${ }^{1}$; A. M. M. FICANHA ${ }^{1}$; A. R. PAULAZZI ${ }^{1}$; J. ZENI ${ }^{1}$; R. M. \\ DALLAGO $^{1}$ \\ ${ }^{1}$ Universidade Regional Integrada do Alto Uruguai e das Missões - URI - Erechim, Departamento de \\ Engenharia de Alimentos \\ E-mail para contato: ilizandrafernandes@yahoo.com.br
}

\begin{abstract}
RESUMO - A imobilização de enzimas em suportes apropriados se constitui em uma área de interesse quanto à melhoria de processos e redução de custos. Sendo assim, o suporte ideal deve adsorver irreversivelmente a enzima, sem interferir na reação enzimática ou afetar sua atividade. Neste contexto, objetivo desse estudo foi avaliar a estabilidade de estocagem em temperaturas ambiente $\left(10-25{ }^{\circ} \mathrm{C}\right)$ e refrigerador $\left(2-8{ }^{\circ} \mathrm{C}\right)$ da enzima lipase Candida antarctica B (CAL B) na forma livre e imobilizada por confinamento em suporte de poliuretano (PU). A estabilidade da CAL B livre apresentou no decorrer de 40 dias de estocagem a temperatura ambiente, atividade residual de $52 \%$ e em refrigerador, $34 \%$. Em contrapartida, o imobilizado em poliuretano mostrou-se em 375 dias de exposição atividades residuais de $87 \%$ e $51 \%$ respectivamente nas mesmas condições. Os resultados mostram que esse biocatalisador imobilizado rendeu um derivado ativo e estável que pode ser aplicado em síntese de ésteres em reatores de leito fixo.
\end{abstract}

\section{INTRODUÇÃO}

As lipases (triacilglicerol ester hidrolases - E.C.3.1.1.3) são biocatalisadores de grande importância em diferentes áreas. São capazes de catalisar reações em meios aquosos ou orgânicos liberando ácidos graxos, diacilglicerois, monoacilglicerois e glicerol (Villeneuve et al., 2000; Singh e Mukhopadhyay 2012).

Além disso, estas enzimas principalmente a lipase B de Candida antarctica (CAL B) são capazes de utilizar vários substratos e são altamente específicas aos seussubstratos, possuem alta atividade para várias reações sob condições brandas, estabilidade térmica, atuação em uma ampla faixa de $\mathrm{pH}$ e elevada estéreo especificidade, dependendo do seu microambiente podem catalisar reaçoes de hidrólise ou síntese de ligações éster, alcoólise, aminólise, peroxidação, epoxidação, esterificação, interesterificação ou transesterificação, sendo assim podem ser usadas em várias reações de interesse industrial (Salum, 2010). Principalmente na produção de compostos opticamente ativos na indústria farmacêutica; produção de ésteres usados na indústria de aromas, síntese de oleato de 


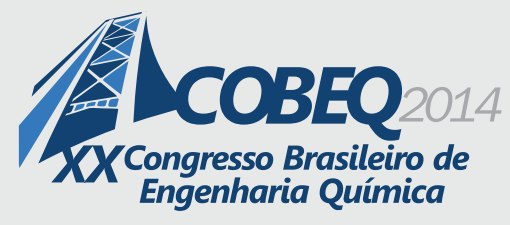

19 a 22 de outubro de 2014

Florianópolis/SC

cetila, um análogo do óleo de cachalote em indústrias de alimentos, síntese de lactato de butila que possui propriedades higroscópicas, emulsificantes e esfoliantes, síntese de ésteres de vitaminas, objetivando tornar estas últimas solúveis em óleo para adição em produtos alimentícios e outras como esterificação de açúcares (Brusamarelo et al., 2010; Moreno e Giraldo 2010; Paroul et al. 2011; Wanderley et al., 2011; Abdelmajeed, 2012; Salihu et al., 2012; Silva et al., 2012),

No entanto, as enzimas na sua forma solúvel são moléculas proteicas complexas e de certa flexibilidade, sua atividade catalítica prove uma estrutura altamente ordenada, muito delicada e frágil, estando sujeitas a inativação por fatores químicos, físicos ou biológicos, durante o seu uso ou estocadas (Richetti et al., 2009). Para que a sua utilização seja economicamente viável e eficiente, as enzimas devem ser melhoradas antes da sua utilização em processos industriais, por exemplo, pela técnica de imobilização. Assim, as lipases imobilizadas podem ser recuperadas após as reações, reutilizadas mais que uma vez, possuir facilidade na remoção da mistura reacional e ser adaptável em vários desenhos de reatores, estes processos, inviáveis quando esta se encontra na forma livre (Torres et al., 2011; Mendes et al., 2013).

As técnicas de imobilização e as condições empregadas durante a imobilização, tipo de suporte, natureza do solvente e variações de reatores podem influenciar nas propriedades das enzimas imobilizadas. Essas condições podem ser moldadas para modificar as propriedades da enzima imobilizada para uso em determinada reação (Idris e Bukhari, 2012). Existem vários métodos para imobilização de lipases, incluindo adsorção, ligação covalente, aprisionamento, encapsulamento e ligaçao cruzada (Dalla-Vecchia et al., 2004; Mendes et al., 2011a e 2011b; Torres et al., 2011; Mendes et al., 2013).

O método utilizado no presente estudo consiste no aprisionamento da enzima numa matriz polimérica. $\mathrm{O}$ biocatalizador pode estabelecer ligações químicas ou físicas com o suporte, mas nesse caso não sofre alterações na sua estrutura. $O$ processo permite modificar a porosidade da matriz, permitindo a passagem das moléculas de massa molecular inferior ao do biocatalisador, sendo assim a possibilidade de modificar quimicamente a matriz, introduzindo unidades eletroquímicas com propriedades óticas que permitem medir sinais de absorvência e fluorescência, aumentar as resistências química e térmica; diminuir a degradação biológica, diminuir efeitos de inchamento, aumentando a atividade enzimática devido aos radicais livres produzidos durante a reação de polimerização e aumento da estabilidade mecânica (Sakai et al., 2010; Zarcula et al. 2010; Jochems et al., 2011; Mendes et al., 2011a; Silva et al., 2012). De acordo com os diversos tipos de suportes usados para imobilização de enzimas o que têm mais se destacado nos últimos anos, é imobilização por confinamento no processo de polimerização em espuma de Poliuretano (PU) principalmente em reações em meio orgânico devido à sua resistência aos solventes orgânicos (Correia et al, 2011) em reações de hidrolise e esterificação (Pires et al., 2007).

A aplicação dos PUs como suportes enzimáticos aplicados em reações em meio orgânico foi descrita por Pires et al. (2007) utilizando Candida rugosa em espumas de poliuretano para produção de etil-butirato. A utilização desse suporte para imobilização de enzimas também foi relatado por Silva et al. (2013) utilizando inulinase de Aspergillus niger, avaliando a estabilidade operacional utilizando sacarose e inulina como substratos. Fernandes et al. (2013) avaliou a imobilização à baixa 
pressão da lipase solúvel de Candida antarctica B em espuma de poliuretano pelo método de encapsulamento/inclusão através da sua utilização do meio reacional para dosagem da atividade de síntese, indicando potencial de ampliação do seu uso em reações de interesse. Santin et al. (2014) utilizou poliuretano na produção de biodiesel utilizando Candida antarctica B (CALB) a baixo custo em lotes de irradiação de ultra-som para a reutilização da enzima.

Neste contexto, o objetivo desse estudo foi avaliar a estabilidade de estocagem em temperaturas ambiente $\left(10-25^{\circ} \mathrm{C}\right)$ e refrigerador $\left(2-8{ }^{\circ} \mathrm{C}\right)$ da enzima lipase de Candida antarctica B (CAL B) na forma livre e imobilizada por confinamento em suporte de poliuretano (PU).

\section{MATERIAIS E MÉTODOS}

\subsection{Materiais}

A imobilização foi realizada utilizando a lipase de Candida antarctica do tipo B (Novozyme NZL-102, CALB), adquirida na forma liofilizada da empresa Novozymes Latin América Ltda. A enzima CALB líquida foi previamente diluída em $\mathrm{H}_{2} \mathrm{O}$, na proporção $0,16 \%$ (v/v) (enzima:água). Os monômeros comerciais poliol e isocianato foram produzidos com uma formulação específica para colchões e espumas injetadas, pela Empresa Flexível Poliuretanos - Mannes. Os solventes utilizado foram acetona (FMaia), ácido Oléico (Vetec), álcool Etílico (Merck) e hidróxido de Sódio (Nuclear).

\subsection{Polimerização e Imobilização}

A reação de polimerização para obtenção do poliuretano (PU) foi realizada variando a razão dos monômeros poliol:isocianato (6:4 (v/v)), segundo metodologia de Silva et al., (2013) modificada em relação a concentração dos mesmos. O procedimento de imobilização da enzima CALB em PU foi realizada na concentração pré-estabelecida da etapa anterior, onde $10 \%$ da enzima diluída foi adicionada ao monômero (Poliol) sendo homogeneizado e em seguida adicionado o isocianato. Em seguida a etapa de polimerização, o poliuretano contendo a enzima (imobilizado) foi mantido durante 24 horas em dessecador para equalização do teor de umidade, para posterior medida da atividade por esterificação, comparando a enzima na sua forma livre.

\subsection{Avaliação da Estabilidade da Enzima Livre e Enzima Imobilizada}

O estudo de estabilidade térmica da CAL B livre foi conduzido em frascos empendorff, com a solução enzimática na concentração equivalente a usada no processo de imobilização $(0,16 \%)$, já o imobilizado foi adicionado em frasco de vidro com tampa nas temperaturas ambiente $\left(10{ }^{\circ} \mathrm{C}\right.$ a $\left.25^{\circ} \mathrm{C}\right)$ e refrigerador $\left(2^{\circ} \mathrm{C}\right.$ a $\left.8^{\circ} \mathrm{C}\right)$.

\subsection{Determinação da atividade de esterificação}

A atividade de esterificação das foi realizada pela quantificação da reação de síntese do ácido oleico e etanol (razão molar 1:1 (v/v)). A reação foi conduzida a $40{ }^{\circ} \mathrm{C}, 160 \mathrm{rpm}$ por $40 \mathrm{~min}$. Esta foi iniciada pela adição da enzima $(0,1 \mathrm{~g})$ ao meio reacional, em frascos de vidro com tampa, mantidos 


\section{9 a 22 de outubro de 2014 \\ Florianópolis/SC}

em agitador orbital. Alíquotas de $500 \mu \mathrm{L}$ foram retiradas do meio reacional em triplicata no início da reação. A cada amostra foram adicionados $15 \mathrm{~mL}$ de uma solução de acetona-etanol (1:1) (v/v) para paralisar a reação e para extração do ácido oleico segundo Paroul et al (2010 e 2011). A quantidade de ácido consumida foi determinada por titulação com $\mathrm{NaOH}$ 0,05 M. Uma unidade de atividade enzimática foi definida como a quantidade de enzima que consome $1 \mu \mathrm{mol}$ de ácido graxo por minuto, nas condições do ensaio segundo Brígida et al. (2010).

\subsection{Cálculo do Rendimento de Imobilização}

O rendimento do imobilizado foi calculado considerando a atividade total da enzima livre em solução (a qual considera o volume de extrato enzimático empregado no ensaio de imobilização) e a atividade total do imobilizado (o qual considera a massa total de imobilizado produzido) de acordo com Brígida et al (2010)

\section{RESULTADOS E DISCUSSÕES}

Testes iniciais demonstram um efeito positivo da massa de enzima adicionada sobre a atividade de esterificação até um determinado percentual, no caso até $0,16 \%$, proporcionando um rendimento na imobilização, considerando à quantidade de enzima livre (160 mg) emprega na etapa de incorporação, e a atividade calculada considerando a atividade total do suporte PU (10,0 g), onde a atividade inicial da enzima livre de 489,2 U/g, proporcionando um imobilizado com atividade de $1149,00 \mathrm{U} / \mathrm{g}$, tendo assim um rendimento de $250 \%$.

O presente estudo comprova a tendência na qual a enzima no seu estado livre apresenta atividade residual inferior a da enzima imobilizada quando armazenada em diferentes temperaturas. A enzima livre apresentou atividade residual de $52 \%$ e $34 \%$ em temperatura ambiente e refrigerador por um período de 40 dias de armazenamento. Em contrapartida, a enzima CAL B imobilizada em PU após 375 dias de armazenamento apresentou comportamento estável com atividade residual de $87 \%$ e $51 \%$ quando armazenadas em temperatura ambiente e refrigeração, respectivamente, conforme mostrados na Figura 1. Esse fato pode ser decorrente do aumento da estabilidade do catalisador ou modificações na estrutura do suporte favorecendo a estabilidade do imobilizado.

O experimento usando a enzima CAL B imobilizado em Accurel (polipropileno) e poliestireno aumentou de três vezes no tempo de estabilidade em relação a enzima livre, que apresentou um tempo de meia vida de apenas 5 dias (Branco et al., 2008). Já o uso da invertase imobilizada em PU obteve uma estabilidade por um período de 60 dias, sem perda considerável atividade $(68,5 \%$ de retenção da atividade) (Cadena et al., 2010).

Muruci et al. (2012) estudaram a enzima de Aspergillus niger em fermentação semi-sólida obterem em 30 dias de estocagem sob refrigeração, a enzima manteve-se com 52,2 \% de atividade residual, porém, com 120 dias houve uma perda de $94 \%$ de sua atividade residual. Giraldo e Díaz (2013) em pré-tratamento de águas residuais na indústria láctea com a lipase Candida rugosa imobilizada em organobentonita no pré-tratamento das águas residuais, obteve em sua pesquisa atividade durante o armazenamento a $4{ }^{\circ} \mathrm{C}$ por uma semana uma excelente estabilidade operacional. 
Na obra de Jeganathan et al., (2006) utilizada uma lipase Candida rugosa para a hidrólise de gorduras, e este pode ser utilizado por 4 ciclos de reação com uma retenção de atividade de $55 \%$. Os resultados deste trabalho, comparados com os da literatura, demostram que o imobilizado de Candida antarctica B em PU apresenta-se como um derivado ativo e estável e pode ser aplicado em síntese de ésteres em reatores de leito fixo.

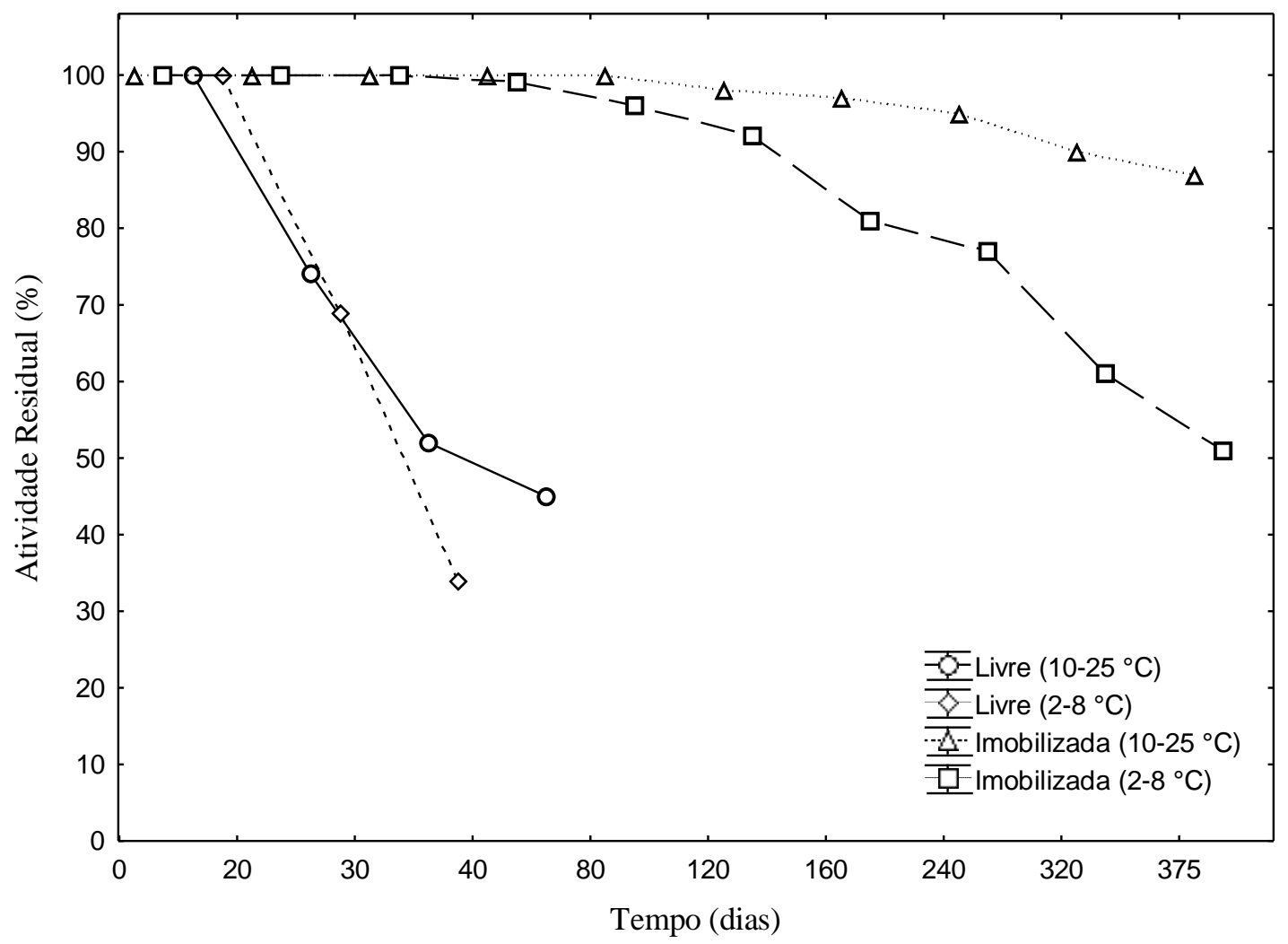

Figura 1 - Comportamento da enzima Candida antarctica B na forma livre e imobilizada em PU submetida a diferentes temperaturas de estabilidade.

\section{CONCLUSÕES}

O processo de imobilização proporcionou um aumento de $\approx 250 \%$ da atividade da enzima imobilizada em relação à livre, este resultado sugere um efeito benéfico da imobilização sobre a atividade da enzima. Estes resultados indicam efeito positivo da imobilização sobre a atividade da enzima, proporcionando uma tendência que pode estar relacionada com varias fatores como a disponibilização, facilidade do acesso de novos sítios ativos, facilidade na separação do meio reacional, sem contaminação do produto final pela enzima e melhor controle do processo e possibilidade da reutilização do biocatalisador imobilizado. A imobilização da lipase CAL B em PU por confinamento no processo de polimerização, é uma técnica promissora, relacionando a simplicidade do processo, o baixo custo do suporte e a capacidade de aplicação do biocatalizador em 
reações de interesse na indústria de alimentos.

\section{REFERENCIAS}

ABDELMAJEED, N. A.; KHELIL, O. A.; DANIAL, E. N. Immobilization technology for enhancing bio-products industry. Afr. J. Biotechnol., v. 11, p. 13528-13539, 2012.

BRANCO, R. V. Imobilização e caracterização de uma Esterase termoestável recombinante de Pyrococcus furiosus. Rio de Janeiro, Dissertação (Mestrado em Bioquímica). Instituto de Química, Universidade Federal do Rio de Janeiro, 2008.

BRÍGIDA, A. I. S.; CALADO, V. M. A.; GONÇALVES, L. R. B.; COELHO, M. A. Z. Effect of chemical treatments on properties of green coconut fiber. Carbyd. Polym., v. 79, p. 832-838, 2010.

BRUSAMARELO, C. Z.; ROSSET, E.; DE CÉSARO, A.; TREICHEL, H.; DE OLIVEIRA, D.; MAZUTTI, M. A.; OLIVEIRA, J. V. Kinetics of lipase-catalyzed synthesis of soybean fatty acid ethyl esters in pressurized propane. J. Biotechnol., v. 147, p. 108-115, 2010.

CADENA, P. G.; JERONIMO, R. A. S, MELO, J. M.; SILVA, R. A.; LIMA FILHO, J. L.; PIMENTEL, M. C. B., Covalent immobilization of invertase on polyurethane, plast-film and ferromagnetic Dacron. Biores. Technol., v.101, p.1595-1602, 2010.

CORREIA, A. C. V. B.; FONSECA, M. M. R.; FERREIRA, D. M. S. L. Produção de emulsionantes através da glicerólise de óleo de bagaço de azeitona catalisada pela lipase da Candida rugosa imobilizada em espumas de poliuretano. Millenium., v. 41, p. 7-15, 2011.

DALLA-VECCHIA, R.; NASCIMENTO, M. DA G.; SOLDI, V. Aplicações sintéticas de lipases imobilizadas em polímeros. Quim. Nova., v. 27, p. 623-630, 2004.

FERNANDES, I. A.; NYARI, N. L. D.; FERRAZ, L. I. R.; DE OLIVEIRA, D.; DE OLIVEIRA, J. V.; RIGO, E. Avaliação da aplicação da lipase Candida antarctica B imobilizada na catálise de reações de síntese. ANAIS DO XIX seminário institucional de iniciação científica, XVII Seminário de Integração de Pesquisa e Pós-Graduação, XI Seminário de Extensão, IV Mostra de Ciência e Tecnologia, v. 17, 2013.

GIRALDO, G. G. I.; DÍAZ, R. M. Pre-tratamiento de aguas residuales de la industria láctea con una lipasa inmovilizada. Produc. Limpia., v. 8, p. 51-59, 2013.

IDRIS, A.; BUKHARI, A. Immobilized Candida antarctica lipase B: Hydration, stripping off and application in ring opening polyester synthesis. Biotechnol Adv., v. 30, p. 550-563, 2012.

JEGANATHAN, J.; BASSI, A.; NAKHLA, G. Pre-treatment of high oil and grease pet food 
industrial wastewaters using immobilized lipase hydrolyzation. J. Hazard. Mater., v. 137, p. 121$128,2006$.

JOCHEMS, P.; SATYAWALI, Y.; DIELS, L.; DEJONGHE, W. Enzyme immobilization on/in polymeric membranes: status, challenges and perspectives in biocatalytic membrane reactors (BMRs). Green Chem., v. 13, p. 1609-1623, 2011.

MENDES, A. A.; DE CASTRO, H. F.; GIORDANO, R. DE L. C. Triagem de Suportes Orgânicos e Protocolos de Ativação na Imobilização e Estabilização de Lipase de Thermomyces lanuginosus. Quim. Nova., v. 36, p. 245-251, 2013.

MENDES, A. A.; GIORDANO, R. C.; GIORDANO, R. D. L.; DE CASTRO, H. F. Immobilization and stabilization of microbial lipases by multipoint covalent attachment on aldehyde-resin affinity: application of the biocatalysts in biodiesel synthesis. J. Mol. Catal. B: Enzym., v. 68, p. 109-115, 2011. ${ }^{\mathrm{a}}$

MENDES, A. A.; OLIVEIRA, P. C. D.; DE CASTRO, H. F.; GIORDANO, R. D. L. Application of chitosan as support for immobilization of enzymes of industrial interest. Quim. Nova., v. 34, p. 831-840, 2011.

MORENO, P. J. C.; GIRALDO, L. Study of immobilized candida rugosa lipase for biodiesel fuel production from palm oil by flow microcalorimetry. Arabian J. Chem., v. 4, p. 55-62, 2011.

MURUCI, L.; SANTOS, R. S.; VIANA, L.; DAMASO, M.; COURI, S.; PENHA, E. D. M Estudo da estabilidade a temperatura, $\mathrm{pH}$ e a estocagem, de lipase produzida por Aspergillus niger em fermentação semi-sólida. ANAIS do Embrapa Agroenergia Blumenau: Fundação Universidade Regional de Blumenau, 2012.

PAROUL, N.; BIASI, A.; ROVANI, A. C.; PRIGOL, C.; DALlAGO, R.; TREICHEL, H.; OLIVEIRA, D. Enzymatic production of linalool esters in organic and solvent-free system. Biop. Bios. Eng., v. 33, p. 583-589, 2010.

PAROUL, N.; GRZEGOZESKI, L. P.; CHIARADIA, V.; TREICHEL, H.; CANSIAN, R. L.; OLIVEIRA, J. V.; DE OLIVEIRA, D. Erratum to: Solvent-free geranyl oleate production by enzymatic esterification. Bioprocess Biosyst. Eng., v. 34, p. 331-337, 2011.

PIRES, C. P.; FONSECA, M. M. R. DA; FERREIRA, S, D. Modelling the production of ethyl butyrate catalysed by Candida rugosa lipase immobilized in polyurethane foams. Biochem Eng J., v. 33, p. 327-337, 2007.

RICHETTI, A. Esterificação enzimática de palmitato de 2-etilexila em sistema livre de solvente. Dissertação (Mestrado em Tecnologia de Processos Químicos e Bioquímicos) Escola de Química da Universidade Federal do Rio de Janeiro, Rio de Janeiro, 2009. 
SAKAI, S.; LIU, Y.; YAMAGUCHI, T.; WATANABE, R.; KAWABE, M.; KAWAKAMI, K. Immobilization of Pseudomonas cepacia lipase onto electrospun polyacrylonitrile fibers through physical adsorption and application to transesterification in nonaqueous solvent. Biotechnol. Lett., v. 32, p. 1059-1062, 2010.

SALIHU, A.; ALAM, M. Z; ABDULKARIM, M. I.; SALLEH, H. M. Lipase production: An insight in the utilization of renewable agricultural residues. Resour. Conserv. Recy., v. 58, p. 3644, 2012.

SALUM, T. F. C. Produção e imobilização de lipase de Burkholderia cepacia LTEB11 para a síntese de ésteres etílicos. Tese (Doutorado em Ciências-Bioquímica). Setor de Ciências Biológicas. Universidade Federal do Paraná, Curitiba, 2010.

SANTIN, C. M.; SCHERER, P. R.; NYARI, N. L. D.; DALLA ROSA, C.; DALLAGO, R. M.; DE OLIVEIRA, D.; OLIVEIRA, J. V. Batch esterification of fatty acids charges under ultrasound irradiation using Candida antarctica B immobilized in polyurethane foam. Biocatal. Agric. Biotechonol., 2014.

SILVA, M. F.; RIGO, D.; MOSSIA, V.; DALlAGO, R. M.; HENRICK, P.; KUHNA, G. O. DE.; ROSA, D. C.; OLIVEIRA, D.; OLIVEIRA, J. V.; TREICHEL, H. Evaluation of enzymatic activity of commercial inulinase from Aspergillus niger immobilized in polyurethane foam. Food Bioprocess. Tech., v. 91, p. 54-59, 2013.

SILVA, S. M. DA C. Imobilização de CAL B em microrreatores. Dissertação (Mestrado em Engenharia Química) Universidade Federal do Rio de Janeiro. Rio de Janeiro, 2012.

SINGH, A. K.; MUKHOPADHYAY, M. Overview of fungal lipase: a review. Appl. Biochem. Biotechnol., v. 166, p. 486-520, 2012.

TORRES S. P.; MARTINEZ, A. DEL M.; CUTIÑO, A. B.; RODRIGUEZ, C. B.; ALCALDE, M.; BALLESTEROS, A. O.; PLOU, F. J. Immobilized biocatalysts: Novel approaches and tools for binding enzymes to supports. Adv. Mater., v. 23, p. 5275-5282, 2011.

VILLENEUVE, P.; MUDERHWA, J. M.; GRAILlE, J.; HAAS, M. J., Customizing lipases for biocatalysis: a survey of chemical, physical and molecular biological approaches. J. Mol. Catal. B: Enzym., v. 9, p. 113-148, 2000.

WANDERLEY, M. D.; NEVES, E.; ANDRADE, J de C., Revisão Aspectos da Produção Industrial de Enzimas. Rev. Citin., v. 1, p. 30-36, 2011.

ZARCUlA, C.; CORICI, L.; CROITORU, R.; URSOIU, A.; PETER, F. Preparation and properties of xerogels obtained by ionic liquid incorporation during the immobilization of lipase by the sol-gel method. J. Mol. Catal. B: Enzym., v. 65, p. 79-86, 2010. 